\title{
Specific features of heat exchangers calculation considering the laminar boundary layer, the transitional and turbulent thermal conductivity of heat carriers
}

\author{
Yuriy Bilonoga ${ }^{1 *}$, Oksana Maksysko² $^{2}$ \\ ${ }^{1}$ Faculty of Food Technologies and Biotechnology, Stepan Gzytsky Natoinal University of Veterinary Medicine and \\ Biotechnologies Lviv, 50 Pekarska, Lviv 79010, Ukraine and Lviv Institute of Economy and Tourism Lviv, Ukraine \\ ${ }^{2}$ Faculty of Food Technologies and Biotechnology, Stepan Gzytsky Natoinal University of Veterinary Medicine and \\ Biotechnologies Lviv, 50 Pekarska, Lviv 79010, Ukraine
}

Corresponding Author Email: yuriy bilonoha@ukr.net

https://doi.org/10.18280/ijht.360102

Received: 13 December 2017

Accepted: 5 March 2018

\section{Keywords:}

laminar boundary layer, average thickness of the laminar boundary layer, overall heat transfer coefficient, shell-and-tube heat exchanger, criterion of turbulent thermal conductivity of the coolant, coefficient of surface tension

\begin{abstract}
The sources of the literature are analyzed in the article on the influence of the average thickness of the laminar boundary layer (LBL) on the heat transfer coefficient of the various heat-conducting systems. Different authors at different times established the explicit correlation dependence of the increase in heat transfer coefficients with a decrease in the average thickness of the LBL. The average thickness of the LBL according to the literature data was reduced in the various ways (using electric or magnetic field for the flow of the liquid, using the nanoparticles in the flow and various of the metallic spiral inserts, etc.). Applying the similarity theory and using dimensionless Euler, Froude and Reynolds numbers in the LBL, and also applying a new surface number, we previously derived the formula for the calculation of the average thickness of the LBL, which in this paper is used to the calculation the overall heat transfer coefficient of the shell-and-tube heat exchanger. We brought out new number of the turbulent thermal conductivity in the LBL transitional zone by the dimensional analysis method. The relations have also been obtained for the calculating of the transitional viscosity and of the transitional thermal conductivity in the transitional zone of the LBL. The article provides the examples the calculation of the shell-and-tube heat exchanger using the classical method and the proposed formulas. The calculation of the resistance of the LBL and the turbulent zones of the refrigerant flows is carried out the taking into account the coefficients of the turbulent thermal conductivity, as well as the coefficients of the surface tension of the liquids. We proposed the calculation of the shell-and-tube heat exchanger using of the refrigerant with an optimum concentration of the propylene glycol in the water $(47 \%)$. The increase of the overall heat transfer coefficient of the heat exchanger is about $10 \%$.
\end{abstract}

\section{INTRODUCTION}

The energy efficiency of the economy of the modern European and the other countries of the world is one of the most important integral indicators of their success. A low indicator of the energy efficiency of the production in a particular country indicates also problems of the economy, environmental and health care [1]. The energy efficiency of the economy largely depends on the possibility of the intensification and optimization of heat exchange processes in the food, processing, pharmaceutical and other industries. In turn, the indicator of the energy efficiency depends on how intensively and optimally the heat exchange equipment operates at a particular enterprise, since the energy losses in this sphere are the most significant. The efficiency of the normalized heat exchangers depends on how correctly and optimally they are chosen at the certain production sites, and what heat carriers are used in them. The heat exchangers that are not optimally selected will always work with a surplus of the thermal energy, and this in the volumes of a country's enterprises imposes a heavy burden on the cost of production.
It is generally known that heat exchangers are calculated from the condition when the heat-carrier in it moves under a developed turbulent regime, where the Reynolds number is about $\mathrm{Re}=15.000$ [2]. Also, the efficiency of heat transfer in heat exchangers largely depends on the behavior of the laminar boundary layer (LBL) at the solid-liquid interface (the wall surface of the heat exchanger - heat transfer fluid), which, according to the results of the work Quadrio, Maurizio and Ricco, Pierre [3] (2011) largely determines the behavior of the turbulent core of the flow. In the work Iype, E. et al. [4] (2012) the molecular-dynamic modeling of the water flow between two platinum plates accurately predicts the formation of a surface monolayer, where thermal jumps occur at the platinum-water interface, which create significant heat-conducting resistances. This surface monolayer of water molecules differs in structure from structure in volume, and it is simply related to the existence of a surface where surface forces act.

We argue [5] (2017) that a strong field of surface tension forces acts on the solid-liquid interface, which keeps fluid flow with the formation of LBL. Based on the forces analysis in the elementary volume of liquid in LBL, we derived a 
formula (1) for calculating the average thickness LBL, where the coefficient of surface tension of the coolant and the hydrophilicity of the wetting surface appear [5].

$$
\delta=\frac{\sqrt{\frac{\sigma \cos \theta d}{\Delta P}}}{K_{t u r b}}
$$

It is noteworthy that many researchers in their works by various methods influence the behavior of LBL in heat exchange systems, in particular in heat exchangers, in order to reduce their total thermal resistance. Currently, there are many ways to intensify heat exchange in heat-exchange equipment. Moghanlou et al. [6] (2007) proposed to impose an electric field on the flow of liquid, which led to an increase in the heat transfer coefficient. Simultaneously, they argued that the electric field reduced the average thickness of LBL or partially destroyed it [6]. Elbashbeshy, E.M.A., et al. [7] (2011) proposed to apply a magnetic field to the liquid flow, which resulted in a decrease in the average thickness of LBL with an increase in the overall heat transfer coefficient.

Rahmana M. M. and Aziz A. (2012) [8] achieved a reduction in the average thickness of LBL and, a significant increase in heat transfer coefficients due to the introduction of nanoparticles $\left(\mathrm{TiO}_{2}-\mathrm{H}_{2} \mathrm{O}, \mathrm{AL}_{2} \mathrm{O}_{3}-\mathrm{H}_{2} \mathrm{O}, \mathrm{Cu}-\mathrm{H}_{2} \mathrm{O}\right)$ into the water flow.

Gulshan K.S. et al. [9] (2017) and Haridas et al. [10] (2015) also introduced $\mathrm{AL}_{2} \mathrm{O}_{3}-\mathrm{H}_{2} \mathrm{O}$ and $\mathrm{SiO}_{2}-\mathrm{H}_{2} \mathrm{O}$ nanoparticles into the water flow and obtained a decrease in the average thickness of LBL and a significant increase in heat transfer coefficients ( $66.5 \%$ on average).

Sha et al. [11] (2017) added $\mathrm{Fe}_{3} \mathrm{O}_{4}$ nanoparticles to water and simultaneously applied a magnetic field to the liquid flow, which significantly reduced the average thickness of LBL, and as a result - increased the heat transfer coefficient.

Rafiee S. E. et al. [12] (2015) investigated the effect of metallic spiral-like inserts on the coefficients of heat transfer in a vortex tube, the presence of which, apparently, also reduced the average thickness of the LBL. In addition, Dipankar De. and others. [13] (2017) suggest the use of metal spiral inserts as structural elements in shell-and-tube heat exchangers for a significant increase in heat transfer coefficients. The authors [13] sought the optimal angles of attack of metal inserts in order to optimize the increase in the heat transfer coefficient in the shell-and-tube heat exchanger with a minimum increase in its hydraulic resistance.

In works [6-13], the general and key factor is that the average thickness of the LBL is responsible for the overall heat transfer coefficient of the entire system, regardless of the way of reducing this thickness (applying an electric or magnetic field on the liquid flow or using nanoparticles or mechanical spiral inserts and etc.).

Some surfactants (SAS) were used Satya V. et al. [14], Ammerman C. N, et al. [15], Ying et al. [16] to increase the heat transfer coefficients of various heat exchange systems. However, the authors of these studies did not explain these improvements, taking into account changes in the average thickness of the LBL arising at the interfaces (solid-liquid, liquid-liquid). However, it is generally known that SAS significantly reduces the coefficients of surface tension of water and other liquids in concentrations close to critical concentrations of micelles (CCM).
It should be noted that all the activities undertaken by researchers to increase the overall heat transfer coefficients of various heat exchange systems run into difficulties in theoretical calculations of heat exchange equipment, since classical exponential empirical equations using Nusselt and Prandtl numbers change, acquiring rather cumbersomes forms. When using any method of increasing the heat transfer coefficient of heat exchangers, it is necessary to again calculate the constants and exponents of the degrees of such equations. These equations are not available for the calculation of heat exchangers with other methods of lowering the thermal resistance. This can be seen most clearly in the work of P. Sivashanmugam [17]. When using different nanofluids in coolants, the Nusselt numbers acquire a rather complex form, since they depend on a variety of factors (the amount of nanoparticles in the coolant, their size, the particle material, the thermal physical characteristics of the base fluid, etc.). These difficulties in the calculation of heat exchangers are indicated by a number of authors, for example V. Gnielinski [18], who proposes to use the Prandtl theory (1944), based on momentum transfer in turbulent heat carrier flows, instead of the Nusselt equations (1909).

Based on the literary analysis, in this work we set ourselves the following tasks:

- check the efficiency of the previously proposed formula for calculating the average thickness of LBL in the pipes and shell of the shell-and-tube heat exchanger [5];

- propose a new formula for calculating the overall heat transfer coefficients in shell-and-tube heat exchangers, taking into account the average thickness of LBL in the pipes and in the space between the pipes and taking into account turbulent thermal conductivities in the turbulent zones of heat carriers;

- propose a new method for calculating heat exchange equipment based on the use of the thermal conductivity of LBL and the turbulent thermal conductivity of the zones of turbulent flow of the coolant;

- to propose a dimensionless number for determining the efficiency of the operation of liquid heat transfer media in heat exchange equipment, as well as new formulas for calculating transitional viscosity and transitional thermal conductivity in the transitional zones LBL of liquid coolants.

\section{RESULTS}

\subsection{A new equation for calculating the overall heat transfer coefficient of the shell-and-tube heat exchanger}

The process of heat transfer will be considered in the example of heating milk in a shell-and-tube heat exchanger. In this case, cold milk is put into pipes of radius $r_{c}$. Hot water is put into the shell space with an equivalent radius $r_{h}$ (Figure $1)$.

The overall heat transfer coefficient of the shell-and-tube heat exchangers is calculated from the well-known equation (2):

$$
U=\frac{1}{\frac{1}{h_{h}}+\frac{\delta_{w}}{k_{w}}+\frac{1}{h_{c}}}
$$

In this case, the convection coefficients $h_{h}$ and $h_{c}$ are calculated from the known equations for the turbulent motion 
of liquids in tubes or shells from known equations (3) and (4), respectively [2], which carry a huge array of experimental data from many authors.

$N u=0.023 \operatorname{Re}^{0.8} \operatorname{Pr}^{0.43}\left(\frac{\operatorname{Pr}}{\operatorname{Pr}_{w}}\right)^{0.25}$

$N u=0.24 \operatorname{Re}^{0.6} \operatorname{Pr}^{0.36}\left(\frac{\operatorname{Pr}}{\operatorname{Pr}_{w}}\right)^{0.25}$

It is obvious that the turbulent core of the flow of hot water in the intertubular space has the maximum velocity and, accordingly, the maximum thermal energy that is transferred to the turbulent core of the cold milk flow. In this case, the heat moves along the chain, passing respectively all the zones of the hot and cold coolant and is transmitted by means of the thermal conductivities of the corresponding zones ( $k_{\text {turb.h }}$, $k_{\text {trans.h }}, k_{w}, k_{\text {trans.c }}, k_{\text {turb.c }}$ ) (Figure 1).

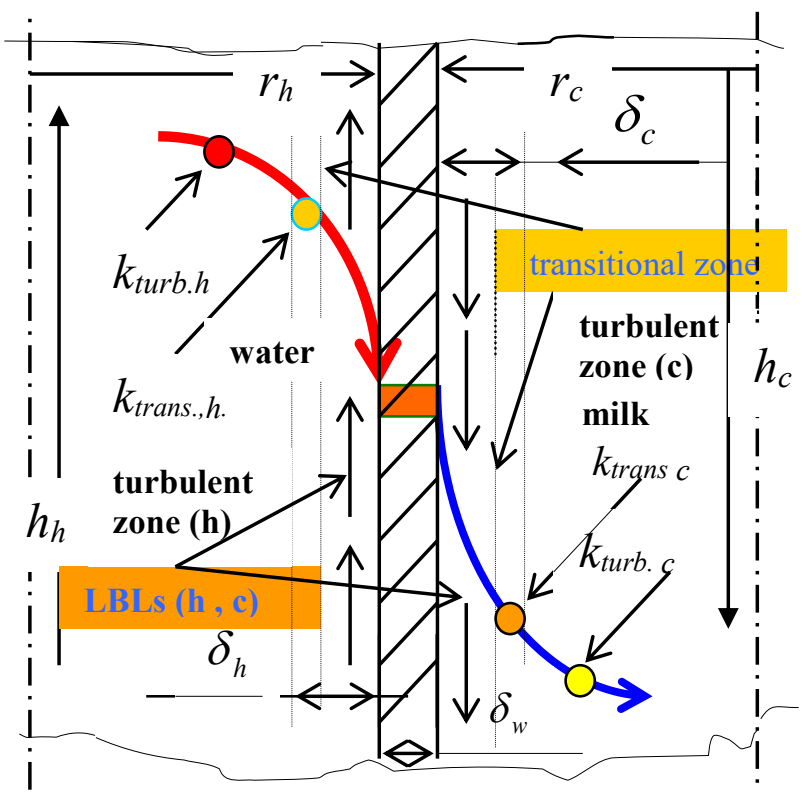

Figure 1. The scheme for transferring the heat through the metal wall from hot water to cold milk

The thermal conductivity of the zones is, of course, different, since the velocity of the coolant in the center of the pipes is maximal, and near the wall it is minimal. However, in equations (3) and (4), in all Nusselt and Prandtl numbers, the molecular thermal conductivity of a stationary fluid appears, which is a two order of magnitude smaller than the turbulent one. Fluid viscosity in the Reynolds number is a two order of magnitude smaller than the turbulent viscosity. In addition, the Reynolds number includes the averaged velocity of the flow. All these discrepancies are hidden by the similarity theory and exponential numerical equations $(3,4)$, where the constants and fractional exponents are calculated experimentally.

The formula derived by us (1) contains the coefficient of the surface tension of the heat carrier and the hydrophilicity of the wetting surface and, in our opinion, are the reflection of such studies by independent authors:

- LBL, namely its average thickness, can significantly affect the overall thermal resistance of the heat exchange system [9, 19];
- the thermal resistance depends on the coefficient of surface tension of the refrigerant [15];

- the intensity of heat exchange depends on the hydrophilicity or hydrophobicity of the wetting surface [20].

Proceeding from the fact that the thermal resistance of the zones depends on the corresponding thermal conductivities and average thicknesses of these zones, we can write the equation of the overall heat transfer coefficient in the form (5). Instead of the convection coefficients $h_{h}$ and $h_{c}$ in the scheme and in formula (5), we used the thermal conductivites and average thickness of all the listed heat exchange zones (Figure 1).

$$
U_{\delta}=\frac{1}{\frac{r_{h}-\delta_{h}}{k_{\text {turb.h }}}+\frac{\delta_{h}}{k_{\text {trans.h }}}+\frac{\delta_{w}}{k_{w}}+\frac{\delta_{c}}{k_{\text {trans.c }}}+\frac{r_{c}-\delta_{c}}{k_{\text {turb.c }}}}
$$

The concept of turbulent viscosity and thermal conductivity was introduced by Joseph Boussinesq's. The fruitfulness of his heritage is shown in the work of Olivier Darrigol (2017) [21].

\subsection{Derivation of equations for calculating the transitional viscosity and thermal conductivity in a LBL}

The derivation of equation of the calculation for transient thermal conductivity in the LBL zone was carried out by the method of analysis of the main dimensions of thermal physical quantities, which is considered effective for optimizing the physicochemical processes of various heat and mass exchange systems.

We have proved that the LBL has a powerful field of surface tension forces, so transient thermal conductivity in the LBL zone depends on such basic factors - the coefficient of surface tension and dynamic viscosity, specific heat of the coolant and can be represented as a function of the exponential (6):

$k_{\text {trans. }}=f\left(\sigma, \mu_{\text {trans }}, c_{p}\right) ; k_{\text {trans. }}=B\left(\sigma^{X}, \mu_{\text {trans }}^{Y}, c_{p}{ }^{2}\right)$

We represent all the thermal physical quantities through the basic dimensions of physical quantities - mass, linear size, time [kg, m, s].

$$
\begin{aligned}
& k_{\text {trans }}-\left[\mathrm{W} \cdot \mathrm{m}^{-1} \cdot \mathrm{K}^{-1}=\mathrm{N} \cdot \mathrm{m} \cdot \mathrm{s}^{-1} \cdot \mathrm{m}^{-1} \cdot \mathrm{K}^{-1}=\mathrm{kg} \cdot \mathrm{m} \cdot \mathrm{s}^{-3} \cdot \mathrm{K}^{-1}\right] ; \\
& \sigma-\left[\mathrm{N} \cdot \mathrm{m}^{-1}=\mathrm{kg} \cdot \mathrm{m} \cdot \mathrm{s}^{-2} \cdot \mathrm{m}^{-1}=\mathrm{kg} \cdot \mathrm{s}^{-2}\right] ; \\
& \mu-\left[\mathrm{N} \cdot \mathrm{s} \cdot \mathrm{m}^{-2}=\mathrm{kg} \cdot \mathrm{m} \cdot \mathrm{s}^{-1} \cdot \mathrm{m}^{-2}=\mathrm{kg} \cdot \mathrm{s}^{-1} \cdot \mathrm{m}^{-1}\right] ; \\
& c_{P}-\left[\mathrm{N} \cdot \mathrm{m} \cdot \mathrm{kg}^{-1} \cdot \mathrm{K}^{-1}=\mathrm{kg} \cdot \mathrm{m}^{2} \cdot \mathrm{s}^{-2} \mathrm{~kg} \mathrm{~g}^{-1} \cdot \mathrm{K}^{-1}=\mathrm{m}^{2} \cdot \mathrm{s}^{-2} \cdot \mathrm{K}^{-1}\right]
\end{aligned}
$$

We write the exponential equation in the form of an equation of dimensions.

$\left[\mathrm{kg}{ }^{1} \cdot \mathrm{m}^{1} \cdot \mathrm{s}^{-3} \cdot \mathrm{K}^{-1}\right]=B\left[\mathrm{~kg} \cdot \mathrm{s}^{-2}\right]^{\mathrm{X}} \cdot\left[\mathrm{kg} \cdot \mathrm{s}^{-1} \cdot \mathrm{m}^{-1}\right]^{Y} \cdot\left[\mathrm{m}^{2} \cdot \mathrm{s}^{-2} \cdot \mathrm{K}^{-1}\right]^{Z} ;$

Starting from the equation of dimensions, we can write such a system of equations for exponents:

$$
\begin{aligned}
& X+Y=1 ; \quad Y=1-X ; \quad-Y+2 Z=1 \\
& Z=1-0.5 X ; \quad-2 X ? Y-2 Z=-3
\end{aligned}
$$




$$
\begin{aligned}
& k_{\text {trans }}=B\left(\sigma^{X} \mu_{\text {trans }}^{1-X} c_{p}^{1-0.5 X}\right) \\
& k_{\text {trans }}=\mu_{\text {trans }} \cdot c_{p}\left(\sigma / \mu_{\text {trans }} \cdot c_{p}^{0.5}\right)^{X}
\end{aligned}
$$

We express powers in one unknown degree of $X$, group all the terms, and obtain equation (7):

$$
\frac{k_{\text {trans }}}{c_{p} \mu_{\text {trans }}}=B\left(\frac{\sigma}{\mu_{\text {trans }} \sqrt{c_{p} \cdot 1^{0} K}}\right)^{X}
$$

Then the right side of the equation is transformed for the transition zone LBL in the form (8).

$$
\frac{1}{B}\left(\frac{\mu_{\text {trans }} \cdot \sqrt{c_{p} \cdot 1^{0} K}}{\sigma}\right)^{X}=1
$$

In equation (7) to the left of the equality sign we obtained the dimensionless Prandtl number in the transitional zone LBL, and to the right - a dimensionless number, named by us the turbulent thermal conductivity number in the transitional zone LBL. Based on the works of Reichardt H., Ludwieg H. $[22,23,24]$ and others, the Prandtl number in the transitional zone of LBL is one. The numerator of the left side of equation (7) is responsible for the transfer of velocity pulses in the cross section of the pipeline, the denominator is responsible for transferring the amount of heat. When the left side of the equation is equal to one, then and the right-hand side is equal to one. The index $X=1$ and the constant $B=1$. Taking into account the hydrophilicity of the surface, equation (8) is transformed into equation (9).

$$
\frac{\mu_{\text {trans }} \sqrt{c_{p} \cdot 1^{0} K}}{\sigma \cdot \cos \theta}=1
$$

In the turbulent flow zone, a turbulent viscosity appears in the middle of the pipeline at so-called free turbulence, which can be calculated from equation (10), which is proposed in the monograph of Pirashvili Sh, et al. (2000) [25]: $a=(0,05-$ $0,08)[25]:$

$$
\mu_{\text {turb }}=\mu \cdot a \sqrt{2 \cdot \operatorname{Re}}
$$

It should be assumed that in the immediate vicinity of the pipe wall the viscosity of the liquid is equal to the dynamic (table) viscosity to which we are accustomed. When removed from the wall, the surface tension forces decrease and in the transitional zone LBL they are approximately equal to the product of frictional forces in LBL and cohesion forces (Figure 1). With further distance from the wall, the transitional viscosity becomes turbulent viscosity and significantly increases from classical dynamic viscosity. The transitional viscosity in the transitional zone LBL, taking into account the relation (9), should be calculated from the formula (11).

$$
\mu_{\text {trans }}=\frac{\sigma \cdot \cos \theta}{\sqrt{C \cdot 1^{0} K}}
$$

It should be noted that when measuring the dynamic viscosity, for example, with the Arrhenius device, the liquid flows through the capillary to form a laminar flow. By doing so, we measure the viscosity, which is substantially increased by the surface forces of the capillary. However, this is not viscosity, which is responsible for frictional forces between the elementary layers of liquid, for example, in the middle of the laminar flow in the pipe.

For the main thermal physical characteristics of water and some other liquids used as coolants, as a function of temperature in Table 1 (Addition), we calculated the values of the transitional viscosity from formula (11), as well as the transitional thermal conductivity according to formula (12), and the value of the turbulent thermal conductivity (criterion) number in the LBL transitional zone by formula (9).

$$
k_{\text {rans }}=\frac{\sigma \cdot \cos \theta \cdot C_{P}}{\sqrt{C_{P} \cdot 1^{0} K}} ;
$$

At temperature of about $20{ }^{\circ} \mathrm{C}$, water passes through the line (marked in Table 1. Addition) when the value of the turbulent thermal conductivity number $(B l)$, calculated by the formula (9), is approximately equal to unity. For aqueous solutions of $36 \%$ ethylene glycol and $25 \%$ propylene glycol, this transition line is about $80{ }^{\circ} \mathrm{C}$ (Table 1 . Addition). The values of dynamic viscosity and transitional viscosity in LBL, as well as thermal conductivity and transient thermal conductivity in LBL are approximately equal (Table 1. Addition). At other temperatures they do not coincide. At a temperature below the red line, the transitional viscosity is less than the classical (tabular) viscosity, since the influence of surface tension forces is very significant. At temperatures above red line, the transitional viscosity already becomes more classical (tabular), since the influence of the surface tension forces weakens, the effect of friction forces increases and in the transitional zone the influence of flow turbulence on the transitional viscosity already exists (Table 1. Addition)

It should be assumed that the existence of a transition zone in LBL is a unique balance between surface forces, cohesion and friction forces in LBL.

The transitional viscosity in the LBL transitional zone should be calculated from formula (11). When calculating the transient thermal conductivity and transitional viscosity in the transitional zone at temperatures different from $20{ }^{\circ} \mathrm{C}$, we must use formulas (12) and (11). In the transitional zone LBL, the product of the cohesion and friction forces divided by the surface tension forces is approximately equal to one. When the temperature of the liquid increases, the cohesion forces are weakened and as a result of the surface tension forces and friction forces decrease (Table 1. Addition). We noticed such transition lines in other liquids, for example, solutions of ethyl alcohol in water of different concentrations, solutions of sugar in water, etc.

\section{CALCULATION OF THE SHELL-AND-TUBE HEAT EXCHANGER}

\subsection{Thermal calculation of the shell-and-tube heat exchanger to the classical method}

To confirm the proposed equations, we calculated and selected a normalized shell-and-tube heat exchanger in accordance with the classical method. 
The shell-and-tube heat exchanger is calculated in which milk at initial temperature $T_{c}$, in $=20{ }^{\circ} \mathrm{C}$ with mass flow rate $m_{c}=12 \mathrm{~kg} \cdot \mathrm{s}^{-1}$ is heated to a final temperature $T_{c}$, out $=65^{\circ} \mathrm{C}$. Heating is provided by water with initial temperature $T_{h \text {, in }}=$ $90{ }^{\circ} \mathrm{C}$. The final temperature of this water is $T_{h}$, out $=75^{\circ} \mathrm{C}$.

1.Thermal and physical properties of milk and water for average temperatures:

- average temperature of cold milk $T_{c}=42.5^{\circ} \mathrm{C}$;

- average temperature of hot water $T_{h}=72.5^{\circ} \mathrm{C}$;

- cold milk: $\rho_{c}=1020 \mathrm{~kg} \cdot \mathrm{m}^{-3} ; \mu_{c}=0.96 \cdot 10^{-3} \mathrm{~kg} \cdot \mathrm{m}^{-1} \cdot \mathrm{s}^{-1}$; $k_{\mathrm{c}}=56.98 \cdot 10^{-2} \mathrm{~W} \cdot \mathrm{m}^{-1} \cdot \mathrm{K}^{-1} ; \sigma_{c}=47.75 \cdot 10^{-3} \mathrm{~N} \cdot \mathrm{m}^{-1}$; $c_{p \mathrm{c}}=3.914 \cdot 10^{3} \mathrm{~J} \cdot \mathrm{kg}^{-1} \cdot \mathrm{K}^{-1}$.

- hot water: $\rho_{h}=970 \mathrm{~kg} \cdot \mathrm{m}^{-3} ; \mu_{h}=0.34 \cdot 10^{-3} \mathrm{~kg} \cdot \mathrm{m}^{-1} \cdot \mathrm{s}^{-1}$;

$$
k_{h}=67.7 \cdot 10^{-2} \mathrm{~W} \cdot \mathrm{m}^{-1} \cdot \mathrm{K}^{-1} ; \sigma_{h}=62.25 \cdot 10^{-3} \mathrm{~N} \cdot \mathrm{m}^{-1} \text {; }
$$$$
c_{p h}=4.198 \cdot 10^{3} \mathrm{~J}_{\mathrm{kg}^{-1}} \cdot \mathrm{K}^{-1} \text {; }
$$

2. Mass flow rate of hot water according to the heat balance equation is:

$\dot{m}_{h}=\frac{\dot{m}_{c} c_{p, c}\left(T_{c, \text { out }}-T_{c, \text { in }}\right)}{c_{p, h}\left(T_{h, \text { in }}-T_{h, \text { out }}\right)}=\frac{12 \cdot 3.914 \cdot 10^{3} \cdot(65-20)}{4.198 \cdot 10^{3} \cdot(90-75)}=33.565 \mathrm{~kg} \cdot \mathrm{s}^{-1}$

3. Approximate overall heat transfer coefficient $U_{a p p}$ is supposed as the minimum value that corresponds to the turbulent flow (Table 2.1. [2]). $U_{a p p}=800 \mathrm{~W} \cdot \mathrm{m}^{-2} \cdot \mathrm{k}^{-1}$, with an approximate value of the Reynolds number for the turbulent mode $\operatorname{Re}=15.000$.

4. The thermal stress:

$$
Q=\dot{m}_{h} c_{p, h}\left(T_{h, \text { in }}-T_{h, \text { out }}\right)=12 \cdot 3.914 \cdot 10^{3} \cdot(65-20)=2113560 \mathrm{~W}
$$

5. The mean logarithmic temperature difference is:

$$
\Delta T_{\text {LMTD }}=\frac{\left(T_{h, \text { in }}-T_{c, \text { in }}\right)-\left(T_{h, \text { out }}-T_{c, \text { out }}\right)}{\ln \frac{\left(T_{h, \text { in }}-T_{c, \text { in }}\right)}{\left(T_{h, \text { in }}-T_{c, \text { out }}\right)}}=\frac{(90-20)-(75-65)}{\ln \frac{90-20}{75-65}}=\frac{70-10}{\ln \frac{70}{10}}=30.8^{\circ} \mathrm{C}
$$

$\Delta T_{L M T D}=30.83 \cdot 0.915=28{ }^{\circ} \mathrm{C}$

0.915 - coefficient of correction of a mixed flow [2].

6. The approximate heat exchange surface area and approximate overall heat transfer coefficient:

$$
\begin{aligned}
& U_{a p p} \approx 800 \mathrm{~W} \cdot \mathrm{m}^{-2} \cdot \mathrm{K}^{-1} \\
& A_{a p p}=\frac{Q}{\Delta T_{L M T D} U_{a p p}}=\frac{2113560}{28 \cdot 800}=94 \mathrm{~m}^{2}
\end{aligned}
$$

7. The ratio of the number of pipes to the number of passes of the shell-and-tube heat exchanger: (for the pipe diameter $d_{\text {out }}$ $\left.=20.10^{-3} \mathrm{~m} ; \delta_{w}=2.10^{-3} \mathrm{~m} ; d_{i n}=16.10^{-3} \mathrm{~m}\right)$ is:

$$
\frac{n}{z}=\frac{4 \dot{m}_{c}}{\pi d_{i n} \operatorname{Re}_{c} \mu_{c}}=\frac{4 \cdot 12}{3.14 \cdot 16 \cdot 10^{-3} \cdot 15000 \cdot 0.96 \cdot 10^{-3}}=66.35
$$

For pipe diameter $d_{\text {out }}=25.10^{-3} \mathrm{~m}, \delta_{w}=2.10^{-3} \mathrm{~m} ; d_{i n}=21.10^{-3} \mathrm{~m}$ :

$$
\frac{n}{z}=\frac{4 \dot{m}_{c}}{\pi d_{i n} \operatorname{Re}_{c} \mu_{c}}=\frac{4 \cdot 12}{3.14 \cdot 21 \cdot 10^{-3} \cdot 15000 \cdot 0.96 \cdot 10^{-3}}=50.55
$$

From Table 2.3 [2] selected options normalized shell-andtubes heat exchangers, in which is close with the heat surface area to $94 \mathrm{~m}^{2}$ and the ratio $\mathrm{n} / \mathrm{z}$ falls into the range $-(50.55 \leq$ $n / z \leq 66.35)$. With the heat surface area:

$A=97 \mathrm{~m}^{2}$ and. The exchanger has parameters:

$D=0.6 \mathrm{~m}, z=4, n / z=51.5 ; n=206, L=6 \mathrm{~m}$. The area $A_{c}=4.5 \cdot 10^{-2} \mathrm{~m}^{2}$ (the cross-sectional area space between the tubes of the heat exchanger; Table 2.3 [2]). Inner diameter of pipes $-d_{\text {in }}=21.10^{-3} \mathrm{~m}$, Outside diameter of pipes $-d_{\text {out }}=$ $25.10^{-3} \mathrm{~m}$. Cold milk is circulated in the pipes and hot water is circulated between pipes.

8. The Reynolds number for the pipes is:

$$
\operatorname{Re}_{c}=\frac{4 \dot{m}_{c}}{\pi d_{i n}\left(\frac{n}{z}\right) \mu_{c}}=\frac{4 \cdot 12}{3.14 \cdot 21 \cdot 10^{-3} \cdot 51.5 \cdot 0.96 \cdot 10^{-3}}=14723.59
$$

- the turbulent mode

9. The Reynolds number for the in the space between the tubes of the heat exchanger is:

$\operatorname{Re}_{h}=\frac{\dot{m}_{h} d_{\text {out }}}{A_{c} \mu_{h}}=\frac{33.565 \cdot 25 \cdot 10^{-3}}{4.5 \cdot 10^{-2} \cdot 0.34 \cdot 10^{-3}}=54836.6-$ the turbulent mode

10. The Prandtl number for cold milk:

$$
P_{r_{c}}=\frac{\mu_{c} c_{p, c}}{k_{c}}=\frac{0.96 \cdot 10^{-3} \cdot 3.914 \cdot 10^{3}}{56.98 \cdot 10^{-2}}=6.59
$$

11. The Prandtl number for hot water:

$$
P_{r_{h}}=\frac{\mu_{h} c_{p, h}}{k_{h}}=\frac{0.34 \cdot 10^{-3} \cdot 4.198 \cdot 10^{3}}{67.7 \cdot 10^{-2}}=2.11
$$

12. The Nusselt number for cold milk from equation (3) [2]:

$$
N u_{c}=0.023 \cdot 14723.59^{0.8} 6.59^{0.43}\left(\frac{6.59}{2.11}\right)^{0.25}=139.95
$$

13. The convection coefficient for cold milk:

$$
\begin{aligned}
& h_{c}=\frac{k_{c} N u_{c}}{d_{i n}}=\frac{56.98 \cdot 10^{-2} \cdot 139.95}{21 \cdot 10^{-3}}=3797.31 \mathrm{~W} \cdot \mathrm{m}^{-2} \cdot \mathrm{K}^{-1} ; \\
& \frac{1}{h_{c}}=2.633 \cdot 10^{-4} \mathrm{~W}^{-1} \cdot \mathrm{m}^{2} \mathrm{~K}
\end{aligned}
$$

14. The Nusselt number for hot water from equation (4) [2]:

$N u_{h}=0.24 \cdot 54834.6^{0.6} 2.11^{0.36}\left(\frac{2.11}{6.59}\right)^{0.25}=164.18$

15. The convection coefficient of hot water:

$h_{h}=\frac{k_{h} N u_{h}}{d_{\text {out }}}=\frac{67.7 \cdot 10^{-2} \cdot 164.18}{25 \cdot 10^{-3}}=4445.99 \mathrm{~W} \cdot \mathrm{m}^{-2} \cdot \mathrm{K}^{-1} ;$

$\frac{1}{h_{h}}=2.249 \cdot 10^{-4} \quad \mathrm{~W}^{-1} \cdot \mathrm{m}^{2} \mathrm{~K}$

16. The pipe wall thickness, $\delta_{w}=2 \cdot 10^{-3} \mathrm{~m}$; 
17. The coefficient of metal pipe thermal conductivity (the pipes are made of stainless steel): $k_{w}=17.5 \mathrm{~W} \cdot \mathrm{m}^{-1} \mathrm{~K}^{-1}$;

18. The overall heat transfer coefficient from the relation (1) with taking into the resistance of fouling (water average quality is, Table $2.2[2])$ :

$$
U=\frac{1}{2.633 \cdot 10^{-4}+\frac{2 \cdot 10^{-3}}{17.5}+2.249 \cdot 10^{-4}+2 \frac{1}{3000}}=788.52 \mathrm{~W} \cdot \mathrm{m}^{-2} \cdot \mathrm{K}^{-1}
$$

$2 \cdot \frac{1}{3000}-$ thermal resistance of contaminants.

19. The heat exchange surface area:

$$
A=\frac{Q}{\Delta T_{\text {LMTD }} U}=\frac{2113569}{28 \cdot 788.52}=95.72 \mathrm{~m}^{2}
$$

20. The mistake of heat exchange surface area:

$$
\frac{97-95.72}{95.72} 100 \%=1.33 \%
$$

\subsection{Hydraulic calculation of the shell-and-tube heat exchanger by the classical method}

1. The total pressure loss in the heat exchanger tubes, with the movement of cold milk, is calculated from the equation [2]:

$\Delta P_{c}=\frac{f L z}{d_{i n}} \cdot \frac{v_{c}^{2} \rho_{c}}{2}+[2,5(z-1)+2 z] \frac{v_{c}^{2} \rho_{c}}{2}+3 \frac{v_{c, n}^{2} \rho_{c}}{2}$

The Darcy coefficient was calculated for the turbulent flow regime of the coolant [2]:

$f=0.11\left(e+\frac{68}{\operatorname{Re}_{\mathrm{c}}}\right)^{0.25} ; \frac{10}{e}<\operatorname{Re}_{c}<\frac{560}{e} ;$

where $e=\frac{\Delta}{d_{i n}} ;\left(\Delta=0.1 \cdot 10^{-3} \mathrm{~m} . ; d_{i n}=21 \cdot 10^{-3} \mathrm{~m}\right)$.

$v_{c}=\frac{4 \dot{m}_{c} z}{\pi d_{i n}^{2} n \rho_{c}}=\frac{4 \cdot 12 \cdot 4}{3,14 \cdot\left(21 \cdot 10^{-3}\right)^{2} \cdot 206 \cdot 1020}=0.659 \mathrm{~m} \cdot \mathrm{s}^{-1}$

$d_{n}=150 \cdot 10^{-3} \mathrm{~m} ;[2$, Table 2.6.]

$v_{c, n}=\frac{4 \dot{m}_{c}}{\pi\left(d_{n}\right)^{2} \rho_{c}}=\frac{4 \cdot 12}{3,14 \cdot\left(150 \cdot 10^{-3}\right)^{2} \cdot 1020}=0.666 \mathrm{~m} \cdot \mathrm{s}^{-1}$

$\Delta P_{c}=\frac{3.42 \cdot 10^{-2} \cdot 6 \cdot 4}{21 \cdot 10^{-3}} \cdot \frac{(0.659)^{2} \cdot 1020}{2}+$

$+[2.5(4-1)+2 \cdot 4] \frac{(0.659)^{2} 1020 \cdot}{2}+3 \frac{1020(0.666)^{2}}{2}=12768.41 \mathrm{~Pa}$.

2. The total loss of pressure in the space between the heat exchanger tubes while hot water passes is calculated by the equation [2].
$\Delta P_{h}=\left(\frac{3 m(x+1)}{\operatorname{Re}_{h}^{0,2}}\right) \cdot \frac{v_{h}^{2} \rho_{h}}{2}+1,5 x \frac{v_{h}^{2} \rho_{h}}{2}+3 \frac{v_{h, f}^{2} \rho_{h}}{2}$

$x=18$ [2, Table 2.7]; $m=\sqrt{n / 3}=\sqrt{206 / 3} \approx 9 ;$

$v_{h}=\frac{\dot{m}_{h}}{A_{c} \rho_{h}}=\frac{33.565}{4.0 \cdot 10^{-2} \cdot 970}=0.865 \mathrm{~m} \cdot \mathrm{s}^{-1}$

$v_{h}=\frac{\dot{m}_{h}}{\pi\left(d_{n}\right)^{2} \rho_{h}}=\frac{33.565}{3,14 \cdot(0.2)^{2} \cdot 970}=0.275 \mathrm{~m} \cdot \mathrm{s}^{-1}$

$\Delta P_{h}=\left(\frac{3 \cdot 9(18+1)}{54836.6^{0,2}}\right) \cdot \frac{0.865^{2} \cdot 970}{2}+1,5 \cdot 10 \frac{0.865^{2} \cdot 970}{2}+$

$+3 \frac{0.275^{2} \cdot 970}{2}=30902.96 \mathrm{~Pa}$

\subsection{Calculation of the shell-and-tube heat exchanger by the new method.}

Nine items of preliminary calculation are similar to the classic.

10. The total pressure loss in the heat exchanger tubes, with the movement of cold milk is $\Delta P_{c}=12768.41 \mathrm{~Pa}$.

11. The total loss of pressure in the inter tube space of the heat exchanger with the movement of hot water is

$\Delta P_{h}=30902.96 \mathrm{~Pa}$.

12. The average thickness of the LBL in the tubes of the heat exchanger according to equation (1):

$$
\delta_{C}=\frac{\sqrt{\frac{47.75 \cdot 10^{-3} \cdot 0.7 \cdot 21 \cdot 10^{-3}}{12768.4}}}{\frac{14723.59}{2320}}=3.678 \cdot 10^{-5} \mathrm{~m}
$$

13. The average thickness of the LBL in the space between the heat exchanger tubes according to equation (1):

$$
\delta_{h}=\frac{\sqrt{\frac{62.25 \cdot 10^{-3} \cdot 0.84 \cdot 25 \cdot 10^{-3}}{30902.96}}}{\frac{54836.6}{1000}}=3.751 \cdot 10^{-6} \mathrm{~m}
$$

The critical value of the Reynolds number in the space between the tubes is $R e_{c r}=1000$ [2];

14. The average thermal conductivity in the transitional zone LBL from the condition that $\operatorname{Pr}_{\text {turb(trans })}=1$ according to equation (12):

- for milk:

$$
k_{\text {trans.c }}=\frac{47.75 \cdot 10^{-3} \cdot 0.7 \cdot 3.914 \cdot 10^{3}}{\sqrt{3.914 \cdot 10^{3}}}=2.09 \mathrm{~W} \cdot \mathrm{m}^{-1} \cdot \mathrm{K}^{-1}
$$

- for water: 
$k_{\text {trans.h }}=\frac{62.25 \cdot 10^{-3} \cdot 0.84 \cdot 4.198 \cdot 10^{3}}{\sqrt{4.198 \cdot 10^{3}}}=3.387 \mathrm{~W} \cdot \mathrm{m}^{-1} \cdot \mathrm{K}^{-1}$

It should be noted that in all the experimental studies listed in the literature, primarily Reichardt H. and Ludwieg H., [22, 23] note that in the transition zone of the LBL the turbulent Prandtl number is always $\operatorname{Pr}_{\text {turb.(trans) }}=1$; or very close to it. It seems to us that it depends on the accuracy of the experiment, and they are carried out by Reichardt $\mathrm{H}$. and Ludwieg H. [22, 23] very carefully. Moreover, the equations deduced by our method of dimensional analysis also indicate that the $P r_{\text {turb. } \text { (trans) }}=1$ in the transition zone of the LBL.

In the middle of the turbulent flow (in the middle of the pipeline) the $\operatorname{Pr}_{t u r b}=2$; or very close to it. For average calculations, the ratio of the pulse coefficients $A_{\tau}$ and the heat coefficients $A_{q}$ in the middle of the pipeline Schlichting $\mathrm{H}$. advises taking the average value between 2 and 1, i.e. $\frac{1}{P_{r_{\text {turb }}}}=\frac{A_{q}}{A_{\tau}}=1.3$ [24]. Then according to Reichardt H., the inverse of the ratio is the turbulent Prandtl number of $\frac{A_{\tau}}{A_{q}}=P_{\text {rturb }}=\frac{1}{1.3}=0.769$ [22].Therefore, in our formulas, in calculation of turbulent thermal conductivities, the average $P r_{\text {turb. }}=0.769$, appears in the denominator.

15. The average turbulent thermal conductivity, taking into account equation (10) $\left(k_{\text {turb. }}=C_{p} \mu_{\text {turb }}\right)$ :

- for milk:

$k_{\text {turb.c }}=\frac{3.914 \cdot 10^{3} \cdot 0,96 \cdot 10^{-3} \cdot 0.07 \sqrt{2 \cdot 14723.59}}{0.769}=58.69 \mathrm{~W} \cdot \mathrm{m}^{-1} \cdot \mathrm{K}^{-1}$

- for water:

$k_{\text {turb.h }}=\frac{4.198 \cdot 10^{3} \cdot 0,34 \cdot 10^{-3} \cdot 0.07 \sqrt{2 \cdot 54836.6}}{0.769}=43.02 \mathrm{~W} \cdot \mathrm{m}^{-1} \cdot \mathrm{K}^{-1}$

16. The overall heat transfer coefficient, taking into account correlation (5), with taking into the resistance of fouling (water average quality, account is Table 2.2 [2]):

$U_{\delta}=\left(\begin{array}{l}\frac{124.962 \cdot 10^{-4}}{43.02}+\frac{3.751 \cdot 10^{-6}}{3.387}+\frac{2 \cdot 10^{-3}}{17.5}+ \\ +\frac{3.678 \cdot 10^{-5}}{2.09}+\frac{104.632 \cdot 10^{-4}}{58.69}+2 \cdot \frac{1}{3000}\end{array}\right)^{-1}=788.7 \mathrm{~W} \cdot \mathrm{m}^{-2} \cdot \mathrm{K}^{-1}$

$2 \cdot \frac{1}{3000}-$ thermal resistance of contaminants.

17. The heat exchange surface area:

$A=\frac{Q}{\Delta T_{L M T D} U}=\frac{2113560}{28 \cdot 788.7}=95.7 \mathrm{~m}^{2}$

18. The reserve of heat exchange surface area:

$\frac{97-95.7}{95.7} 100 \%=1.35 \%$
19. The error of calculating the overall heat transfer coefficient by the classical and the new method:

$\frac{788.7-788.52}{788.52} 100 \%=0.023 \%$

This calculation confirms that the intensity of heat transfer in flows with turbulent regimes depends on the average thicknesses of the LBLs and on the averages thicknesses of the turbulent zones of the coolants streams.

We got the same heat exchanger as in the classic calculation. This calculation was performed taking into account LBL and turbulent thermal conductivities of coolant flows. The classical calculation is based on numerical equations that carry huge experimental material, and the proposed calculation uses experimental data from the works of Reichardt H., Ludwieg H. and Schlichting H. and others. The coincidence error is less than $0,05 \%$.

The novelty of our calculation method is manifested primarily in the fact that in calculating the overall heat transfer coefficient of the heat exchanger, we used not the Nusselt number, but the values of the thermal conductivity and the average thickness of the individual heat exchange zones (Figure 1). In the heat exchange zones, the LBL zone is identified separately, where a new formula (1) is used to calculate the average thickness of LBL and new formulas (9, $11,12)$ are used to calculate the mean transitional thermal conductivities of these LBL zones taking into account the coefficients of surface tension of heat carriers. In addition, the values of the turbulent thermal conductivities of the turbulent heat exchange zones are calculated, taking into account formula (10). It seems to us that the new method is more compact, especially when calculating heat exchangers with multicomponent heat carriers, for example, when using nanofluids.

\subsection{Calculation of the shell-and-tube heat exchanger by the new method when using surfactants in heat carriers}

In the new coolant, the propylene glycol additive to water in the concentrations of $47 \%$ was selected from the following conditions:

- the use of propylene glycol is considered safe for the production of food products and medicines. Based on propylene glycol, oral and injectable medications such as diazepam and lorazepam are created;

- the properties of propylene glycol make it possible to use it in anti-icing fluids for airplanes and antifreezes for automobiles, in air conditioning, ventilation and heating systems in residential buildings, in food cooling systems and other heat exchange equipment;

- this fluid has an optimal ratio of the most important thermal physical characteristics over a wide range of operating temperatures (Table 1 Addition);

- this liquid is not volatile, that is prematurely it does not evaporate from the aqueous solution, in contrast to solutions of different alcohols;

- the optimal thermal physical characteristics at optimal Reynolds numbers for turbulent thermal conductivity are in propylene glycol with a concentration of $47 \%$ in water.

- as a surfactant to milk, pumpkin oil was used in concentration of $0.5 \%$ [5].

Changes in the thermal physical characteristics of heat carriers and the overall heat transfer coefficient of the shell- 
and-tube heat exchanger under the influence of additives of optimal concentrations are given in Table 2 (Addition). The overall heat transfer coefficient of the heat exchanger is increased nearly on $10 \%$ : $\frac{860.5-788.7}{788.7} 100 \% \approx 10 \%$.

\section{CONCLUSIONS}

1. The formulas derived by us $(1,9,11,12)$ confirm the studies of authors on the dependence of the overall heat transfer coefficient of heat exchangers on such basic factors:

- LBL, namely its average thickness, can significantly affect the overall thermal resistance of the heat exchange system $[9,19]$;

- the thermal resistance depends on the coefficient of surface tension of the refrigerant [15];

- the intensity of heat exchange depends on the hydrophilicity or hydrophobicity of the wetting surface [20].

2. We proposed and tested the formula, for calculating the overall heat transfer coefficient in five different normalized shell-and-tube heat exchangers, which includes the thermal resistances LBL on both sides of the boundary metal wall and the thermal resistances of the turbulent zones of the carrier flows.

3. The new method for calculating and selecting heat exchangers is proposed, based on the use of formulas that determine the average thicknesses of LBL on both sides of the boundary metal wall, taking into account the thermal resistances of the turbulent zones of the coolant. The example of such a calculation is given.

4. The similar result for the selection of an optimal normalized heat exchanger was obtained by the classical and proposed method. The error was less $0,023 \%$. The maximum effect is manifested in the propylene glycol refrigerant with a concentration of $47 \%$ in water.

5. Formulas for calculation of transitional viscosity and transitional thermal conductivity in the LBL transitional zone have been obtained and tested. The increase in the overall heat transfer coefficient of heat exchangers depends not only on the average thickness of the LBL, but also on the optimum ratio of thermal physical values of the refrigerants.

6. The existence of a transition zone in LBL is a unique balance between surface forces, cohesion and friction forces in LBL.

7. We obtained a dimensionless complex-a number that shows the ratio of friction forces and intermolecular interaction forces to surface tension forces at a given coolant temperature. We designated it as $(B l)$. Thus, this number shows the possibility of maximum heat transfer in conditions of turbulent thermal conductivity of heat carriers and heat transfer through LBL under given temperature conditions at optimum Reynolds numbers.

8. The new method is more compact, especially when calculating heat exchangers with multicomponent heat carriers, for example, with nanofluids.

\section{REFERENCES}

[1] Mirandola A, Lorenzini E. (2016). Energy, environment and climate: from the past to the future. International Journal of Heat and Technology 34(2): 159-164. http://dx.doi.org/10.18280/ijht.340201
[2] Dytnerskij Y.I. (1991). Basic processes and devices of chemical technology (Manual of engineering). Moskwa, Chemistry, 14-70.

[3] Quadrio M, Ricco P. (2011). The laminar generalized Stokes layer and turbulent drag reduction. Journal of Fluid Mechanics 667: 135-157. http://dx.doi.org/ 10.1017/S0022112010004398

[4] Iype E, Arlemark EJ, Nedea SV, Rindt CCM, Zondag HA. (2012). Molecular dynamics simulation of heat transfer through a water layer between two platinum slabs. 6th European Thermal Sciences Conference (Eurotherm 2012), France.

[5] Bilonoga Y, Maksysko O. (2017). Modeling the interaction of coolant flows at the liquid-solid boundary with allowance for the laminar boundary layer. International Journal of Heat and Technology 35(3): 678-682. http://dx.doi.org/ 10.18280/ijht.350329

[6] Farhad Sadegh M, Amin Shams K, Esmaeil E. (2007). Experimental study on electrohydrodynamically induced heat transfer enhancement in a minichannel. Experimental Thermal and Fluid Science 59(2): 24-31. https://doi.org/ 10.1016/j.expthermflusci

[7] Elbashbeshy EMA, Bazid MAA, Aldawody DA. (2011). Effect of magnetic field on boundary layer flow over an unsteady stretching surface in a micropolar fluid. International Journal of Heat and Technology 29(1): 69-74. http://dx.doi.org/ 10.18280/ijht.290111

[8] Rahmana M.M, Aziz A. (2012). Heat transfer in water based nanofluids $\left(\mathrm{TiO}_{2}-\mathrm{H}_{2} \mathrm{O}, \mathrm{Al}_{2} \mathrm{O}_{3}-\mathrm{H}_{2} \mathrm{O}\right.$ and $\left.\mathrm{Cu}-\mathrm{H}_{2} \mathrm{O}\right)$ over a stretching cylinder. International Journal of Heat and Technology 30(2): 31-42. http://dx.doi.org/ 10.18280/ijht.300205

[9] Gulshan KS, Atul S. (2017). Exploring the potential of nanofluids for heat transferaugmentation in dimpled compact channels: Non-intrusive measurements. International Journal of Heat and Mass Transfer 108 (Part. A): 1140-1153. https://doi.org/ 10.1016/j.ijheatmasstransfer.2016.12.085

[10] Haridas D, Rajput NS, Atul S. (2015). Interferometric study of heat transfer characteristics of $\mathrm{Al}_{2} \mathrm{O}_{3}$ and $\mathrm{SiO}_{2}-$ based dilute nanofluids under simultaneously developing flow regime in compact channels. International Journal of Heat and Mass Transfer 88: 713-727. 10.1016/j.ijheatmasstransfer.2015.05.027

[11] Sha LL, Ju YL, Zhang H. (2017). Experimental investigation on the convective heat transfer of $\mathrm{Fe}_{3} \mathrm{O}_{4} /$ water nanofluids under constant magnetic field. Applied Thermal Engineering 113: 566-574. https://doi.org/ 10.1016/j.applthermaleng.2016.11.060

[12] Rafiee SE, Sadeghiazad MM. (2015), 3D numerical analysis on the effect of rounding off edge radius on thermal separation inside a vortex tube. International Journal of Heat and Technology 33(1): 83-90. http://dx.doi.org/ 10.18280/ijht.330112

[13] Dipankar D, Tarun KP, Santanu B. (2017). Helical baffle design in shell and tube type heat exchanger with CFD analysis. International Journal of Heat and Technology 35(2): 378-383. http://dx.doi.org/ 10.18280/ijht.350221

[14] Ravikumar SV, Jha JM, Mohapatra SS, Pal SK, Chakraborty S. (2014). Experimental Investigation of effect of different types of surfactants and jet height on 
cooling of a hot steel plate. J. Heat Transfer 136(7). http://dx.doi.org/ 10.1115/1.4027182

[15] Ammerman CN, You SM. (1996). Determination of the boiling enhancement mechanism caused by surfactant addition to water. J. Heat Transfer 118(2): 429-435. http://dx.doi.org/ 10.1115/1.2825862

[16] Tzan YL, Yang YM. (1990). Experimental study of surfactant effects on pool boiling heat transfer. J. Heat Transfer 112(1): 207-212. http://dx.doi.org/ $10.1115 / 1.2910346$

[17] Sivashanmugam P. (2012). Application of nanofluids in heat transfer. An Overview of Heat Transfer. Phenomena.Chapter $14 . \quad$ http://dx.doi.org/ $10.5772 / 52496$

[18] Gnielinski V. (1976). New equations for heat and mass transfer in turbulent pipe and channel flow. International Chemical Engineering 16(2): 359-368.

[19] Vlachou MC, Lioumbas JS, Kostantinos D, Chasapis D, Karapantsios TD. (2017). Effect of channel height and mass flux on highly subcooled horizontal flow boiling. Experimental Thermal and Fluid Science 83: 157-168. http://dx.doi.org/ 10.1016/j.expthermflusci.2017.01.001

[20] Caplan ME, Giri A, Hopkins PE. (2014). Analytical model for the effects of wetting on thermal boundary conductance across, solid/classical liquid interfaces. The Journal of Chemical Physics 140 (15): 154701. http://dx.doi.org/ 10.1063/1.4870778

[21] Darrigol O. (2017). Joseph Boussinesq's legacy in fluid mechanics. Comptes Rendus Mécanique 345(7): $427-$ 445. http://dx.doi.org/ 10.1016/j.crme.2017.05.008

[22] Reichardt H. (1944). Impuls - und Wärmeaustausch bei freier Turbulenz. ZAMM, 24, pp. $268-272$.

[23] Ludwieg H. (1956). Bestimmung des Verhältnisses der Austauschkoeffizient für Wärme und Impuls bei turbulenten Grenzschichten, ZFW 4, pp. 73 - 81.

[24] Schlichting H. (1979). Boundary - Layer Theory., pp. 706-712+752-755

[25] Pirashvili SA, Polyaev VM, Sergeev MN. (2000). Vortex effect. experiment, theory, technical solutions, Moscow. UNPU, Energomash, 170-179.

[26] Vargaftik NB. (1972) Handbook on the thermophysical properties of gases and liquids, Nauka, Moscow, 43-53.

[27] Dymlent HE, Kazansky KS, Miroshnikov AM. (1976) Glycols and other derivatives of oxides of ethylene and propylene, Moscow, Chemistry, 38-44+172-194.

\section{NOMENCLATURE}

A heat transfer area, $\mathrm{m}^{2}$

$A_{c} \quad$ cross-sectional area, $\mathrm{m}^{2}$

a experimental coefficient

$B \quad$ unknown constant

$c_{p} \quad$ specific heat capacity, $\mathrm{J}_{\mathrm{kg}} \mathrm{kg}^{-1} . \mathrm{K}^{-1}$

$\cos \theta \quad \operatorname{cosine}$ of the contact angle, dimensionless

$d \quad$ diameter of the pipeline, $\mathrm{m}$

$d_{\text {in }} \quad$ inner diameter of pipes

$d_{n} \quad$ diameter of the nozzles

$d_{\text {out }} \quad$ outside diameter of pipes

D shell diameter, $\mathrm{m}$

$f \quad$ hydraulic frictiocn coefficient

$h \quad$ convective heat transfer coefficient, W. $\mathrm{m}^{-2} \cdot \mathrm{K}^{-1}$

$k$ thermal conductivity, W. $\mathrm{m}^{-1} \cdot \mathrm{K}^{-1}$

$K_{\text {turb }} \quad$ coefficient of turbulence $k_{\text {trans }} \quad$ transitional thermal conductivity in the LBL transition zone, $\mathrm{W} \cdot \mathrm{m}^{-1} \cdot \mathrm{K}^{-1}$;

$k_{t u r b, c} \quad$ coefficient of average turbulent thermal conductivity of cold milk, W. $\mathrm{m}^{-1} \cdot \mathrm{K}^{-1}$;

$k_{t u r b, h} \quad$ coefficient of average turbulent thermal conductivity of hot water, W. $\mathrm{m}^{-1} \cdot \mathrm{K}^{-1}$;

$L \quad$ length of the pipeline, $m$

$m \quad$ number of rows of the pipes

$\dot{m} \quad$ mass flow rate, $\mathrm{kg} . \mathrm{s}^{-1}$

$n \quad$ number of the tubes

$\mathrm{Nu} \quad$ Nusselt number

Pr Prandtl number

$\triangle P \quad$ pressure drop along the pipe or unit, $\mathrm{Pa}$

$Q \quad$ thermal stress, W

$r_{c} \quad$ radius of the "live section" of the cold carrier stream, m;

$r_{h} \quad$ radius of the "live section" of the hot carrier stream, m;

Re Reynolds number

$T$ temperature, ${ }^{\circ} \mathrm{C}$

$T_{L M T D} \quad \log$ mean temperature difference, ${ }^{\circ} \mathrm{C}$

$U$ the overall heat transfer coefficient, $\mathrm{W} . \mathrm{m}^{-2} \cdot \mathrm{K}^{-1}$

$U_{\delta} \quad$ the overall heat transfer coefficient at the averge thickness of the LBL, W. $\mathrm{m}^{-2} . \mathrm{K}^{-1}$

$v_{c} \quad$ speed of the milk, m.s. ${ }^{-1}$

$v_{h} \quad$ speed of the water, $\mathrm{m} . \mathrm{s}^{-1}$

$v_{h, n} \quad$ speed of the water in the nozzles, $\mathrm{m} \cdot \mathrm{s}^{-1}$

$v_{c, n} \quad$ speed of the milk in the nozzles, $\mathrm{m} . \mathrm{s}^{-1}$

$x \quad$ number of segmental partitions

$X \quad$ unknown degree

$Y \quad$ unknown degree

$z \quad$ number of the passes

Z unknown degree

\section{Greek symbols}

$\delta \quad$ average thickness of the LBL, $\mathrm{m}$

$\delta_{w} \quad$ thickness of the tube wall, $\mathrm{m}$

$e \quad$ relative roughness of the pipe, $\mathrm{m}$

$\mu \quad$ dynamic viscosity coefficient, $\mathrm{kg} \cdot \mathrm{m}^{-1} \mathrm{~s}^{-1}$

$\mu_{\text {trans }} \quad$ coefficient of transitional viscosity of coolant, $\mathrm{kg} \cdot \mathrm{m}^{-1} \mathrm{~s}^{-1}$

$\mu_{\text {turb }} \quad$ coefficient of turbulent viscosity of coolant, $\mathrm{kg} \cdot \mathrm{m}^{-1} \mathrm{~s}^{-1}$

$\rho \quad$ fluid density, $\mathrm{kg} \cdot \mathrm{m}^{-3}$

$\sigma \quad$ surface tension coefficient of coolant, N.m ${ }^{-1}$

$\Delta \quad$ pipe roughness, $\mathrm{m}$

\section{Subscripts}

$\begin{array}{ll}a_{p p} & \text { approximate value } \\ c & \text { cold } \\ c r & \text { critical } \\ \text { in } & \text { input } \\ h & \text { hot } \\ \text { LBL } & \text { laminar boundary layer } \\ \text { LMTD } & \text { log mean temperature difference } \\ \text { out } & \text { output } \\ \text { SAS } & \text { surfactants } \\ \text { trans } & \text { transitional } \\ \text { turb } & \text { turbulent } \\ w & \text { wall }\end{array}$




\section{appendix}

Table 1. Basic thermal physical values and thermal physical values in LBL for water and some other liquids used as coolants as a function of temperature (values of thermal physical values for water and ethylene glycol, propylene glycol are taken from the sources $[26,27])$

\begin{tabular}{|c|c|c|c|c|c|c|c|c|c|}
\hline $\begin{array}{l}\text { Tempe- } \\
\text { rature } \\
{\left[t,{ }^{\circ} \mathrm{C}\right]}\end{array}$ & $\begin{array}{c}\text { Density, } \\
\rho \\
{\left[\mathrm{kg} \cdot \mathrm{m}^{-3}\right]}\end{array}$ & $\begin{array}{c}\text { Heat } \\
\text { capacity } \\
C_{p} \\
{\left[\mathrm{~kJ} \cdot \mathrm{kg}^{-1} \mathrm{~K}^{-1}\right]}\end{array}$ & \begin{tabular}{|c} 
Thermal \\
conductivity, \\
$k$ \\
{$\left[\mathrm{~W} \cdot \mathrm{m}^{-1} \mathrm{~K}^{-1}\right]$}
\end{tabular} & $\begin{array}{c}\text { Dynamic } \\
\text { viscosity } \\
\mathrm{x} 10^{-3}, \\
\mu \\
{\left[\mathrm{N} . \mathrm{s.m}^{-2}\right]}\end{array}$ & $\begin{array}{c}\text { Surface } \\
\text { tension } \\
\mathrm{x} 10^{-3}, \\
\sigma \\
{\left[\mathrm{N} \cdot \mathrm{m}^{-1}\right]}\end{array}$ & $\begin{array}{l}\text { The average } \\
\text { thermal } \\
\text { conductivity } \\
k=C_{P} \mu \\
{\left[\mathrm{W} \cdot \mathrm{m}^{-1} \cdot \mathrm{K}^{-1}\right]}\end{array}$ & 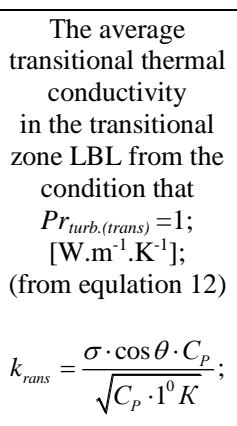 & $\begin{array}{c}\text { The average } \\
\text { transitional } \\
\text { viscosity in the } \\
\text { transitional } \\
\text { zone LBL x } 10^{-3} \\
\operatorname{Pr}_{\text {turb.trans) }}=1 ; \\
{[\text { N.s.m }} \\
\text { (from equlation 11) } \\
\mu_{\text {trans }}=\frac{\sigma \cdot \cos \theta}{\sqrt{C \cdot 1^{0} K}}\end{array}$ & $\begin{array}{l}\text { The number of } \\
\text { transitional thermal } \\
\text { conductivity } \\
B l=\frac{\mu \sqrt{C_{P} \cdot 1^{0} K}}{\sigma \cdot \cos \theta}\end{array}$ \\
\hline \multicolumn{10}{|c|}{ Thermal physical properties of water $\left(\mathrm{H}_{2} \mathrm{O}\right)$} \\
\hline 0 & 999,8 & 4,217 & 0,569 & 1,788 & 75,64 & 7,540 & 3,929 & 0,932 & 1,$919 ; \cos \theta=0,8$ \\
\hline 10 & 999,7 & 4,191 & 0,574 & 1,306 & 4,16 & 5,473 & 3,888 & 0,928 & 1,$407 ; \cos \theta=0,81$ \\
\hline 20 & 998,2 & 4,183 & 0,599 & 1,004 & 72,69 & 4,199 & 3,854 & 0,922 & 1,089; $\cos \theta=0,82$ \\
\hline 30 & 995,7 & 4,174 & 0,618 & 0,801 & 71,22 & 3,343 & 3,818 & 0,915 & 0,$876 ; \cos \theta=0,83$ \\
\hline 40 & 992,2 & 4,174 & 0,519 & 0,653 & 69,65 & 2,72 & 3,772 & 0,906 & 0,$721 ; \cos \theta=0,84$ \\
\hline 50 & 988 & 4,181 & 0,533 & 0,549 & 67,69 & 2,295 & 3,720 & 0,890 & 0,$616 ; \cos \theta=0,85$ \\
\hline 60 & 983,2 & 4,182 & 0,659 & 0,469 & 66,22 & 1,961 & 3,715 & 0,881 & 0,$533 ; \cos \theta=0,86$ \\
\hline 70 & 977,8 & 4,187 & 0,668 & 0,406 & 64,35 & 1,699 & 3,619 & 0,865 & 0,$469 ; \cos \theta=0,87$ \\
\hline 80 & 971,8 & 4,195 & 0,674 & 0,355 & 62,59 & 1,489 & 3,564 & 0,850 & 0,$417 ; \cos \theta=0,88$ \\
\hline 90 & 965,3 & 4,208 & 0,680 & 0,315 & 60,72 & 1,325 & 3,510 & 0,833 & 0,$378 ; \cos \theta=0,89$ \\
\hline 100 & 958,4 & 4,220 & 0,683 & 0,282 & 58,86 & 1,190 & 3,438 & 0,815 & 0,$346 ; \cos \theta=0,90$ \\
\hline \multicolumn{10}{|c|}{ Thermal physical properties $36 \%$ an aqueous solution of ethylene glycol $\left(\mathrm{C}_{2} \mathrm{H}_{6} \mathrm{O}_{2}\right)$} \\
\hline $70^{\circ} \mathrm{C}$ & 1028 & 3,76 & 0,477 & 0,853 & 55,94 & 3,20 & 2,847 & 0,757 & 1,$253 ; \cos \theta=0,83$ \\
\hline $\mathbf{8 0}^{\circ} \mathrm{C}$ & 1022 & 3,78 & 0,478 & 0,695 & $\mathbf{5 4 , 7 7}$ & 2,63 & 2,831 & 0,748 & 1,189; $\cos \theta=0,84$ \\
\hline $100^{\circ} \mathrm{C}$ & 1010 & 3,84 & 0,480 & 0,515 & 52,52 & 1,98 & 2,77 & 0,720 & $0,7148 \cos \theta=0,85$ \\
\hline \multicolumn{10}{|c|}{ Thermal physical properties of $25 \%$ an aqueous solution of propylene glycol; (1,2-Propylene glycol $\left.\mathrm{C}_{3} \mathrm{H}_{6}(\mathrm{OH})_{2}\right)$} \\
\hline $60^{\circ} \mathrm{C}$ & 1003 & 4,03 & 0,505 & 0,903 & 46,48 & 3,639 & 2,951 & 0,732 & 1,$486 ; \cos \theta=0,84$ \\
\hline $80^{\circ} \mathrm{C}$ & 986 & 4,05 & 0,519 & 0,671 & 44,31 & 2,718 & 2,397 & 0,592 & 1,$134 ; \cos \theta=0,85$ \\
\hline $100^{\circ} \mathrm{C}$ & 979 & 4,08 & 0,533 & 0,509 & 42,14 & 2,077 & 2,315 & 0,568 & 0,$898 ; \cos \theta=0,86$ \\
\hline
\end{tabular}

Table 2. Changes in the thermophysical characteristics of heat carriers and the overall heat transfer coefficient of the shell-andtube heat exchanger under the influence of additives of optimal concentrations

\begin{tabular}{|c|c|c|c|c|}
\hline Volume & Cold milk & Hot water & $\begin{array}{l}\text { Cold milk + 0,5\%, } \\
\text { pumpkin oil (SAS) }\end{array}$ & $\begin{array}{l}\text { Hot water }+47 \% \\
\text { propylene glycol }\end{array}$ \\
\hline Density, $\rho$, kg.m ${ }^{-3}$ & 1020 & 970 & 1020 & 995 \\
\hline Dynamic viscosity: $\mu, \mathrm{kg} \cdot \mathrm{m}^{-1} \cdot \mathrm{s}^{-1}$ & $0.96 \cdot 10^{-3}$ & $0.34 \cdot 10^{-3}$ & $0.94 \cdot 10^{-3}$ & $1.08 \cdot 10^{-3}$ \\
\hline Surface tension: $\sigma, \mathrm{N}^{-\mathrm{m}^{-1}}$ & $47.75 \cdot 10^{-3}$ & $62.25 \cdot 10^{-3}$ & $35.25 \cdot 10^{-3}$ & $37.62 \cdot 10^{-3}$ \\
\hline Heat capacity: $c_{p}, \mathrm{~J} \mathrm{~kg}^{-1} \cdot \mathrm{K}^{-1}$ & $3.914 \cdot 10^{3}$ & $4.198 \cdot 10^{3}$ & $3.914 \cdot 10^{3}$ & $3.84 \cdot 10^{3}$ \\
\hline Thermal conductivity: $k, \mathrm{~W} \cdot \mathrm{m}^{-1} \cdot \mathrm{K}^{-1}$ & $56.98 \cdot 10^{-2}$ & $67.7 \cdot 10^{-2}$ & $56.98 \cdot 10^{-2}$ & $39.1 \cdot 10^{-2}$ \\
\hline Reynolds number : Re & 14723.59 & 54836.6 & 15036.86 & 17265.94 \\
\hline The total pressure loss: $\Delta P, \mathrm{~Pa}$ & 12768.41 & 30902.96 & 12744.27 & 35452.42 \\
\hline The average thickness of the LBL: $\delta, \mathrm{m}$ & $3.678 .10^{-5}$ & $3.751 .10^{-6}$ & $3.325 .10^{-5}$ & $8.697 .10^{-6}$ \\
\hline Transitional thermal conductivity: $k_{\text {trans }}, \mathrm{W} \cdot \mathrm{m}^{-1} \mathrm{~K}^{-1}$ & 2.09 & 3.387 & 1.76 & 1.98 \\
\hline Turbulent thermal conductivity: $k_{\text {turb }}, \mathrm{W} \cdot \mathrm{m}^{-1} \mathrm{~K}^{-1}$ & 58.69 & 43.02 & 58.07 & 70.15 \\
\hline Thermal resistance LBL: $\frac{\delta}{k}$, m.K.W ${ }^{-1}$ & $1.759 .10^{-5}$ & $1.571 .10^{-6}$ & $1.886 .10^{-5}$ & $4.382 .10^{-6}$ \\
\hline $\begin{array}{l}\text { Thermal resistance of } \\
\text { the turbulent zones: } \frac{r-\delta}{k_{\text {turb }}}, \mathrm{m} . \mathrm{K} \cdot \mathrm{W}^{-1}\end{array}$ & $1.783 .10^{-4}$ & $2.905 .10^{-4}$ & $1.802 .10^{-4}$ & $1.781 .10^{-4}$ \\
\hline Overall heat transfer coefficient: $U, \mathrm{~W} \cdot \mathrm{m}^{-2} \cdot \mathrm{K}^{-1}$ & \multicolumn{2}{|c|}{788.7} & \multicolumn{2}{|c|}{860.5} \\
\hline
\end{tabular}

